\title{
Identification and Characterisation of Major Hydrocarbons in Thermally Degraded Low Density Polyethylene Films
}

\section{*11ELETTA, OMODELE AA; ${ }^{2}$ AJAYI, OA; ${ }^{3}$ OGUNLEYE, OO; ${ }^{1}$ TIJANI, IA; ${ }^{1}$ ADENIYI, AG; ${ }^{1}$ AGBANA, AS}

\author{
${ }^{I}$ Department of Chemical Engineering, University of Ilorin. Ilorin. Nigeria. \\ ${ }^{2}$ Department of Chemical Engineering, Ahmadu Bello University, Zaria. Nigeria. \\ ${ }^{3}$ Department of Chemical Engineering, Ladoke Akintola University of Technology, Ogbomoso. Nigeria. \\ "Corresponding author: modeletta@unilorin.edu.ng; modeletta@hotmail.com +2348035817674
}

\begin{abstract}
The vast application of Low Density Polyethylene (LDPE) in packaging, greenhouses, homes etc has led to its huge accumulation as a municipal solid waste with monumental health, economic and environmental consequences. Since these are non-biodegradable and their photodegradation occurs only over a very long period, their economic conversion to energy products through pyrolysis is the thrust of this study. LDPE sample collected from the University of Ilorin Community was thermally degraded in a pyrolyser at temperatures ranging from $203-400{ }^{\circ} \mathrm{C}$. The products of pyrolysis were in three (3) states of matter and both the liquid and solid products were analysed using FTIR to determine the functional groups and GC- MS for the hydrocarbons present in the products. For the GC-MS analysis, the peaks that had $90 \%$ above quality when compared with the compounds in the installed NIST11 library were reported. There were alkanes, alkenes, halogenated alkanes, and very few aromatics in the liquid product and, the hydrocarbons were observed to range between $\mathrm{C}_{10}-\mathrm{C}_{27}$. The FTIR and GC-MS results show the potential of the oil obtained as renewable source of energy while that for residue shows its inherent energy content. The liquid product was refluxed over molecular sieve catalyst (US 2882244A) and the calorific value was found to increase from $13,974 \mathrm{~kJ} / \mathrm{kg}$ to $15,815.52 \mathrm{~kJ} / \mathrm{kg}$ and this is found to be comparable to the range for lignite and dry wood. (C) JASEM
\end{abstract}

https://dx.doi.org/10.4314/jasem.v21i6.20

Key words: environmental pollution, solid wastes, LDPE, pyrolysis, hydrocarbons, Calorific value.

Plastic constitutes a major component of Municipal Solid Waste (MSW) because of its intensive use and applications in household, packaging, agricultural, automotive and building construction due to their lightweight characteristics, high chemical stability and low degradability (Ratnasari et a l., 2016; Miandad, et al., 2016). Generation of MSW has increased majorly because of population growth and industrialization and, this has resulted in pressure on the environment, human health and the management of generated solid waste. The composition of MSW depends on many factors such as, level of industrialization, source and seasons. Their characterization is based on the source and rate of generation (Senthilkumar et al., 2013; Palanivel and Sulaiman, 2014).

Plastic wastes are considered as a potentially economic source of chemicals and energy that could be used after its initial useful life has expired since it is derived from petroleum products (UNEP, 2009). This new research drive is in response to the increased search for alternatives that will not only be cheaper, but will be environment friendly and satisfy the energy need of man because of the depletion of conventional sources of energy. Plastics are polymers which have a molecular structure consisting mainly or completely of large number of monomers bond together and the molecular bonds contain hydrogen, carbon and few other elements such as nitrogen, chlorine and others that make plastic very durable (Anuar Sharuddin et al, 2016). Typical forms of plastics are, low density polyethylene, polypropylene, polystyrene, high density polyethylene, terephthalate, poly vinyl chloride, polycarbonate among others (UNEP, 2009; Gaurav et al, 2014; Miandad et al ,2016).

Low Density Polyethylene (LDPE) is a widely-used plastic for making component parts of equipment, packaging in the industry, in grocery stores, in agriculture for green houses and its use results in the generation of large volume of plastic wastes (Anuar Sharuddin et al, 2016). The wastes unfortunately are only photodegradable over a very long time and so occupy large volume of space and thus constituting fundamental problems from environmental and economic point of views (Sovova et al, 2008; Lin, 2009).

In Nigeria, MSW are disposed indiscriminately and because of the non - biodegradable nature of the plastic wastes, it has resulted in their accumulation and sometimes these get washed into drainages and lead to flooding during rains (Ademiluyi and Akpan, 2007). Also, photo- degradation could turn plastic waste over time into dusts which can enter the food chain and even trigger respiratory problems for individuals that are allergic to dust (Senthilkumar et al, 2013). 
Various methods available for disposal of waste plastics include incineration (Hopewell et al, 2009), landfill, recycling (Martin- Gullon et al, 2001; Nizami et al., 2015) and pyrolysis (Nizami et al., 2015). Pyrolysis involves the breakdown of the plastics into more useful products under controlled conditions of temperature, air with or without catalysts (Das and Pandey, 2007). It is a thermo chemical degradation reaction and results in the production of oil, gas and waxes (Miskolczi et al, 2006).

Thermal degradation of plastics has been known to follow several pathways simultaneously and this leads to a broad product range (Lin, 2009). Both homo and heterogeneous catalysts have been employed in studies on catalytic cracking of plastics and, heterogeneous catalysts have been preferred. Previous catalysts used in pyrolysis include, zeolite ZSM 5 (Sarker et al, 2012), BEA, US-Y,MOR, lead sulphide, modified nanocrystalline and amorphous silica - aluminas. Some had contacted melted polymer with catalyst (Ohkita et al, 1993, Aguado et al, 2006, Aguado et al, 2007). Studies have been carried out on thermal degradation of polystyrene wastes (Saker et al, 2012), polyethylene terephthalate (Martin - Gullon et al, 2001), and mixtures of polystyrene and polyethylene wastes (Miskolczi et al, 2006) into fuel oils.

Recycling and recovery methods have been used to minimize the negative environmental impact of improper disposal of plastic wastes. However, these methods account for less than $10 \%$ of plastic wastes disposed and are characterized by other economic and health challenges (Syamsiro et al., 2014) .The need to find a solution to the problems arising from plastic wastes informed this research which is aimed at thermal degradation of low density polyethylene wastes to fuel oil.

\section{MATERIALS AND METHOD:}

\section{Feedstock collection and preparation; The}

feedstock for this study were the waste packaging of sachet water that were mainly LDPE. This plastic type was selected as it forms a major component of MSW found in the University of Ilorin, Nigeria. The samples were collected from the specially fabricated and located waste bins located strategically, at shops in the University of Ilorin and, with the help of the shop owners and research assistants; collection of LDPE waste packaging for water was done. The samples were sorted, washed, dried and cut into smaller sizes with the aid of a shredder.
Experimental setup for the pyrolysis: A laboratory scale pilot pyrolysis reactor was commissioned and used for the conversion of LDPE waste into liquid oil and char (Plate 1).

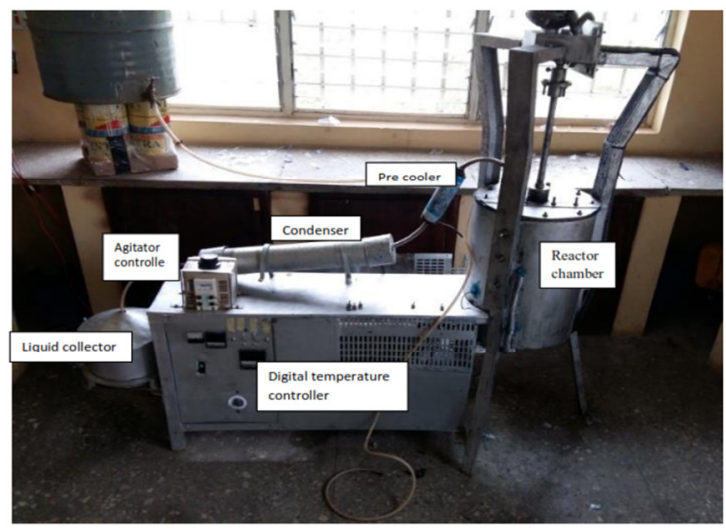

Plate 1: A laboratory scale pyrolysis rig

It consists of the stainless reactor chamber covered with a loop of an electric heater that allows a maximum temperature of $1000^{\circ} \mathrm{C}$; a tube type condenser enhanced with a $2 \mathrm{hp}$ chiller after condensing with a stream of cold water to ensure optimum conversion of organic vapours to liquid oil. The condensed organic vapors (liquid oil) were collected from the liquid collector at the bottom of the system and the uncondensed gases (minimal) coming from same liquid oil pipe were exhausted outside. The char was collected from the reactor chamber at the end of each batch experiment.

Feedstock of LDPE of $3.8 \mathrm{~kg}$ weight was thermal degraded in the pyrolyser at a temperature ranging from 203 to $400^{\circ} \mathrm{C}$ and a resident time of 60 minutes when the first drop of liquid was observed to the last drop. The feedstock was converted into organic vapours that were condensed into liquid oil after passing through the condenser and collected in the liquid collector. The temperature of the condenser chamber was kept below $10^{\circ} \mathrm{C}$ using a 2 hp chiller to achieve the maximum condensation of organic vapours. The unburnt feedstock (char) was collected from reactor chamber at the end of the experiment after allowing the system to cool down at room temperature. At the end of the experiment, a mass balance of pyrolysis products was established through weighing of liquid oil, char quantities and the remaining weight percentage to make up to $100 \%$ was all assumed to be lost as gases.

Analysis of Pyrolytic Products: The liquid oil and residue produced were analyzed using Fourier Transform Infrared Spectroscopy (FTIR) for the functional groups and Gas Chromatography - Mass 
Spectrophotometer (GC-MS) (Agilent USA hyphenated to a mass spectrometer 5975C model) was used to determine the hydrocarbons in the liquid oil. Calorific value of the liquid oil was determined using Bomb Calorimeter (model KA C2000). Specific gravity, Baume and API gravity were determined using a density meter (DOM 2911Rodolph Research Analytical) while other physical properties of the oil were also determined using standard methods.

Catalytic Reflux of oi: $200 \mathrm{ml}$ of oil was refluxed over $2.5 \mathrm{~g}$ UOP Molecular Sieve Catalyst at $100{ }^{\circ} \mathrm{C}$ for an hour and, the end product was characterized.

\section{RESULT AND DISCUSSION}

Product recovery from LDPE pyrolysis: The percentage distribution of the liquid oil, waxy residue (char) and the gaseous products recovery from the pyrolysis of $3.8 \mathrm{~kg}$ of LDPE at a temperature of $400^{\circ}$ $\mathrm{C}$ for 60 minutes is as shown on Figure 1. The liquid oil constituted the highest percentage of the products (78.40\%) followed by the residue $(17.20 \%)$ and the organic gases $(4.40 \%)$. This result may be because LDPE has more branching that result in weaker intermolecular force, thus lower tensile strength and hardness and causes the structure to be less crystalline and easy to be pyrolysed to oil products. This result agrees with the previous results of Uddin et al. (1996) using batch reactor at $430^{\circ} \mathrm{C}$, the liquid yield obtained was $75.6 \mathrm{wt} \%$ and Aguado et al. (2007) with oil yield of 74.7 wt \%. A range of oil and residue products were obtained depending on the operating conditions of temperature and precooling rate (plate 3 and plate 4 ).

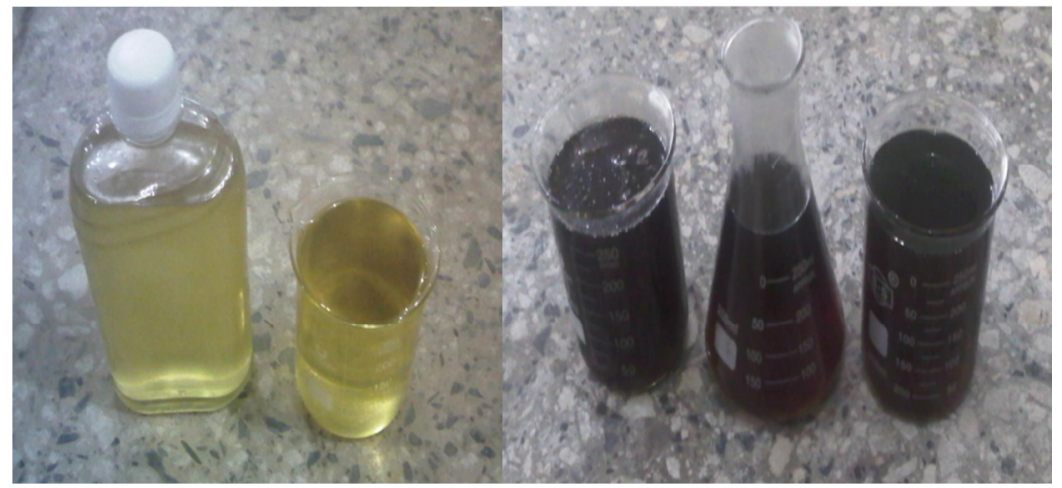

Plate 3: Liquid Products Range

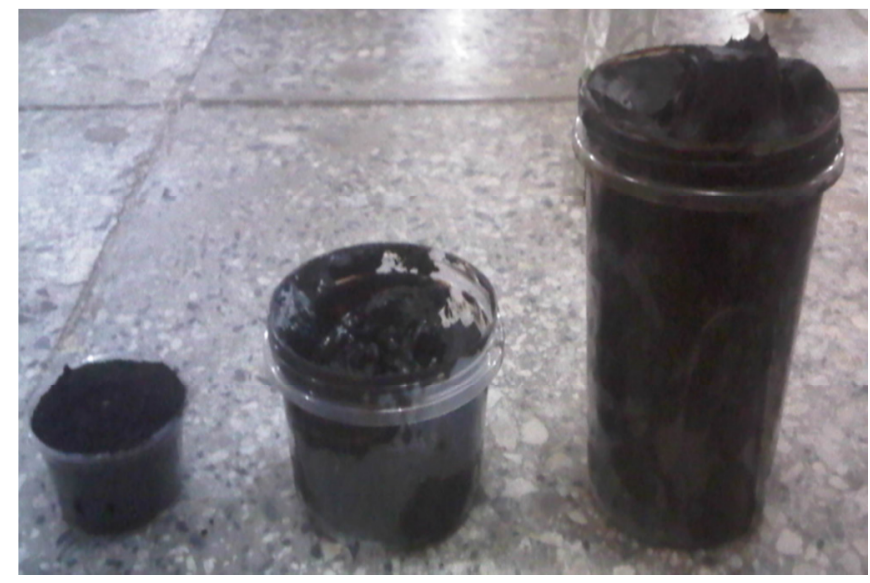

Plate 4: Solid Product Range

The observed reverse in percentage residue and organic gas products may be as a result of the double cooling employed in this set up (Plate 1). 


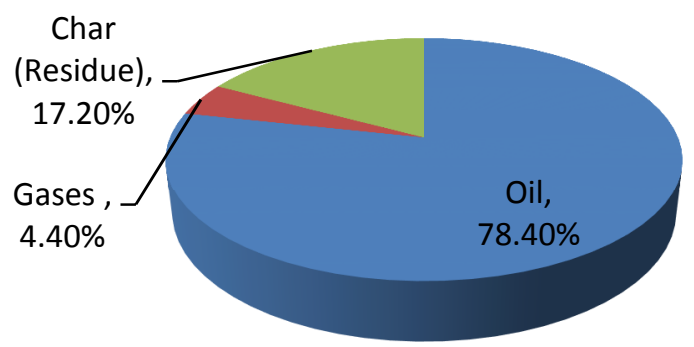

Fig 1: Percentage distribution of LDPE pyrolysis products

Chemical composition of the LDPE pyrolysis products: Both the oil and residue were subjected to FTIR analysis and the findings are as shown in the Figures 2 and 3, respectively as well as Table 1 . The infrared spectrum of the oil showed the C-H stretching of aliphatic alkanes at 2924 and $2854 \mathrm{~cm}^{-1}$ with an observed shoulder of $\mathrm{C}-\mathrm{H}$ stretching of aromatic at $3030 \mathrm{~cm}^{-1}$. Moisture peak indicating the presence of moisture was observable at $2360 \mathrm{~cm}^{-1}$. The vibration of the $\mathrm{C}=\mathrm{C}$ stretching of unsaturation was depicted as a shoulder at 1645 and (sharp) 1462 $\mathrm{cm}^{-1}$ while the $\mathrm{C}-\mathrm{H}$ bending vibration of alkanes and alkenes was observed at $1375 \mathrm{~cm}^{-1}$. There was no visible peak representing the $\mathrm{O}-\mathrm{H}$ and $\mathrm{N}-\mathrm{H}$ vibrations while the carbonyl stretching of $\mathrm{C}=\mathrm{O}$ was also not depicted. The sample appears to be predominantly aliphatic/aromatic hydrocarbons.

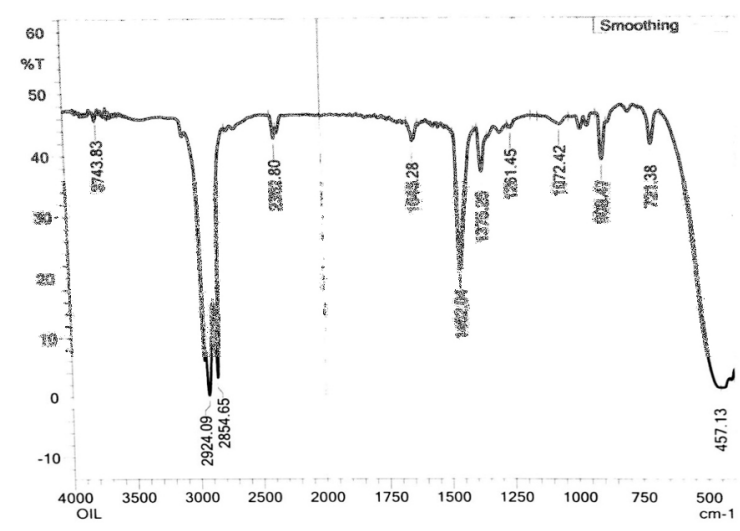

Fig 2: FTIR spectrum for oil
The infrared spectrum of the residue depicted C-H stretching of aliphatic alkanes at 2920 and $2850 \mathrm{~cm}^{-1}$. Moisture peak indicating the presence of moisture was also observed at $2362 \mathrm{~cm}^{-1}$. The weak peak at $1716 \mathrm{~cm}^{-1}$ was assigned to carbonyl stretching vibration while the vibration of the $\mathrm{C}=\mathrm{C}$ stretching of unsaturation was depicted at 1645 and $\mathrm{CH}_{2}$ scissoring at $1463 \mathrm{~cm}^{-1}$. The $\mathrm{C}-\mathrm{H}$ bending vibration of alkanes/alkenes was observed at $1373 \mathrm{~cm}^{-1}$. C-H outof-plane bending was observed as a sharp peak at the fingerprint region $723 \mathrm{~cm}^{-1}$. The very weak peak at $3618 \mathrm{~cm}^{-1}$ could be attributed to $\mathrm{O}-\mathrm{H}$ stretching of alcohol. The presence of $\mathrm{C}-\mathrm{H}$ and $\mathrm{C}=\mathrm{C}$ hydrocarbon groups in plastic waste oil indicate that the liquid has a good potential to be used as fuel. The $=\mathrm{C}=\mathrm{CH}$ was only found in the residue at around $804 \mathrm{~cm}^{-1}$ bandwidth

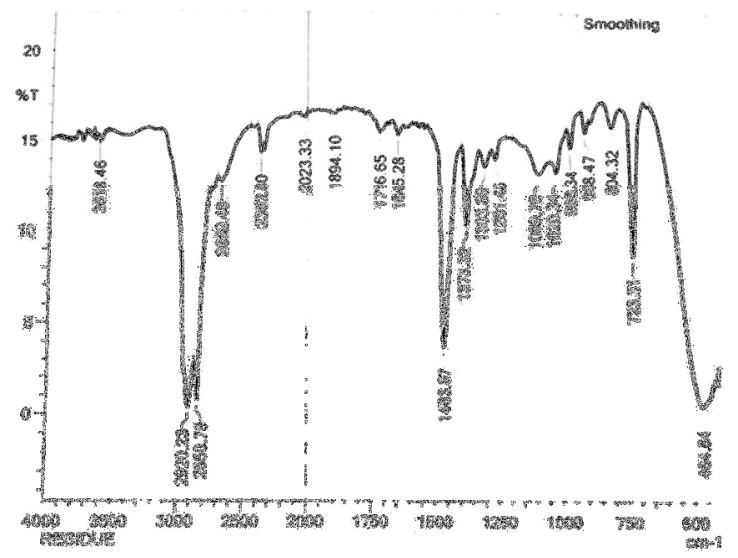

Fig 3: FTIR spectrum for residue 
Table 1: Functional Groups in Pyrolysis Oil and Residue

\begin{tabular}{lll}
\hline Wave number, $\mathbf{~ c m}^{-1}$ & Type of vibration & Name of functional group \\
\hline 2924 & C-H stretching & Alkane \\
2854 & C-H scissoring and bending & Alkane \\
1645 & C=C stretching & Alkene \\
1462 & C=C stretching & Alkene/fingerprint region \\
1375 & C-H stretching & alkane/fingerprint region \\
1072 & C-H bending & Alkane \\
908 & C-H out-of-plane bending & Alkane \\
804 & $=\mathrm{C}=\mathrm{C}-\mathrm{H}$ bend & \\
721 & C-H bend & Alkenes bands \\
\hline
\end{tabular}

The GC- MS analysis of the liquid product was carried out and compounds having peaks with quality of $90 \%$ and above are identified and the number of carbon in each chain was determined and their tentative assignments were confirmed in agreement with the published GC-MS data for comparable products. Compounds assigned and their peak qualities are as shown on Table 2. It can be seen from GC-MS results that the waste LDPE pyrolysis gave liquid products that are very complex mixture, containing many aliphatic and aromatic compounds as presented in the Table 2 . The liquid product from the pyrolysis of waste polyethylene waste is made up of numerous hydrocarbons, alkane, alkene, cyclic and halogenated hydrocarbons.

Table 2: Compounds in pyrolysis oil (GC- MS)

\begin{tabular}{|c|c|c|c|}
\hline SN & Compound & $\begin{array}{l}\text { Peak } \\
\text { quality }\end{array}$ & Description \\
\hline 1 & Benzene, 1,2,3,5 - tetramethyl- $\mathrm{C}_{10} \mathrm{H}_{14}$ & 93 & $\begin{array}{l}\text { Contains only carbon and hydrogen atoms and is a natural } \\
\text { constituent of crude oil with high octane number }\end{array}$ \\
\hline 2 & $\begin{array}{l}\text { Benzene, } 1-\text { methyl-4-(1 methylpropyi) } \\
\mathrm{C}_{10} \mathrm{H}_{14} \mathrm{O}\end{array}$ & 91 & A constituent of heavy fuel oil (Sarker et al., 2012) \\
\hline 3 & Naphthalene, decahydro-2,6-dimethyl- $\quad \mathrm{C}_{12} \mathrm{H}_{22}$ & 92 & \\
\hline 4 & Nanhthalene $\mathrm{C}_{1} \mathrm{H}_{2}$ & 96 & $\begin{array}{l}\text { Has a density of } 0.838 \mathrm{~g} / \mathrm{cm}^{3} \text { and a flash point of } 74.3{ }^{\circ} \mathrm{C} \\
\text { A constituent of fuel oil (Bendebane et al 2010) }\end{array}$ \\
\hline 5 & Dodecane $\quad \mathrm{C}_{12} \mathrm{H}_{26}$ & 96 & $\begin{array}{l}\text { Have been used in a blend in military diesel engine in } \\
\text { varied ratios with } n \text { - hexadecane (Hamilton et al, 2012) }\end{array}$ \\
\hline 6 & Undecane, 2,6-dimethyl $\mathrm{C}_{13} \mathrm{H}_{28}$ & 94 & \\
\hline 7 & $\begin{array}{l}\text { Decahydro-4,4,8,9,10-pentamethylnaphthalene } \\
\mathrm{C}_{15} \mathrm{H}_{28}\end{array}$ & 97 & $\begin{array}{l}\text { Reported as fraction of Nigerian gulf heavy crude oil } \\
\text { (Odebunmi and Ismaeel, 2012) }\end{array}$ \\
\hline 8 & Naphthalene, 1 ethyl- $\quad \mathrm{C}_{12} \mathrm{H}_{12}$ & 95 & \\
\hline 9 & Tetradecane $\quad \mathrm{C}_{14} \mathrm{H}_{30}$ & 96 & \\
\hline 10 & Pentadecane $\mathrm{C}_{15} \mathrm{H}_{32}$ & 96 & \\
\hline 11 & Tridecane & 93 & \\
\hline 12 & Hexadecane $\quad \mathrm{C}_{16} \mathrm{H}_{34}$ & 98 & \\
\hline 13 & 2-bromo dodecane $\mathrm{C}_{12} \mathrm{H}_{25} \mathrm{Br}$ & 90 & \\
\hline 14 & Heptadecane $\quad \mathrm{C}_{17} \mathrm{H}_{36}$ & 98 & \\
\hline 15 & Octadecane $\quad \mathrm{C}_{18} \mathrm{H}_{38}$ & 97 & \\
\hline 16 & Nonadecane $\quad \mathbf{C}_{19} \mathbf{H}_{40}$ & 97 & \\
\hline 17 & Eicosane $\mathrm{C}_{20} \mathrm{H}_{42}$ & 99 & \\
\hline 18 & Hexacosane & 94 & \\
\hline 19 & Heneicosane & 98 & \\
\hline 20 & Heptadecane $\mathrm{C}_{17} \mathrm{H}_{36}$ & 97 & \\
\hline 21 & Tetracosane $\quad \mathrm{C}_{24} \mathrm{H}_{50}$ & 98 & \\
\hline 22 & Pentacosane & 98 & \\
\hline
\end{tabular}

Physico-chemical Characterization of liquid product: Some physical properties of the liquid oil obtained were determined and compared to the properties of the catalysed fuel oil as shown on Table 3. The calorific values (which represents the quantity of heat produced by its combustion under standard conditions) of the raw oil and the catalysed oil were $13,974 \mathrm{~kJ} / \mathrm{kg}$ and $15,815.52 \mathrm{~kJ} / \mathrm{kg}$, respectively which is in the range of lignite and dry wood fuels. The catalyzed process was found to have improved the calorific value of the oil. Others are specific gravity, kinematic viscosity, flash point, and pour as summarised on Table 3. These properties of the liquid oil produced are in good agreement with the standard. The calorific value represents the quantity of heat produced by its combustion under standard conditions 
Table 3: Physico-chemical characterization of liquid product

\begin{tabular}{lll}
\hline Fuel Properties & (Refluxed over catalyst) & Fuel Properties (Raw) \\
\hline Calorific value $(\mathrm{kJ} / \mathrm{kg})$ & $15,815.52$ & 13,974 \\
Moisture content $(\%)$ & $3-5 \%$ & $3-5 \%$ \\
Density g/cm $\mathrm{cm}^{3} @ 15^{\circ} \mathrm{C}$ & 0.795 & 0.812 \\
Flash point $\left({ }^{\circ} \mathrm{C}\right)$ & - & $60-70$ \\
Fire point $\left({ }^{\circ} \mathrm{C}\right)$ & - & $180-185$ \\
Kinematic viscosity $(\mathrm{cSt})$ & & 18.3 \\
Baume & 45.86 & 42.20 \\
Fuel API Gravity & 46.25 & 48.25 \\
\hline
\end{tabular}

Conclusions: This study presents an efficient, clean and very effective means of recycling the waste LDPE. The pyrolysis products consist of a mixture of gas, liquid, and solid fractions. The various analysis carried out on liquid oil produced suggest that the oil has both chemical composition, physical properties and calorific value that are well suited for fuel oil. Since the properties of the oil improved with reflux over a catalyst, further work is to be carried out on the optimization of the catalysed process using, a three factor Central Composite Design in Response Surface Methodology. Factors to be considered are reflux time, catalyst dosage and temperature of reflux.

Acknowledgement: The team would like to acknowledge the Management of the University of Ilorin and the Tertiary Education Trust Fund for the grant to carry out the research. Our appreciation also go to the research assistants who assisted at the various stages of research, and the entire crew of Technologists at the Chemical Engineering, Food, and Agricultural \&Biosystems Engineering laboratories at the University of Ilorin and the Technologists at the Chemical Engineering and Chemistry Departments, Ladoke Akintola University of Technology, Ogbomoso. Nigeria. Mr Amos Sanjo and $\mathrm{Mr} \mathrm{K}$. Jimoh (Welders), $\mathrm{Mr} \mathrm{A}$. Dimeji (Refrigerator man), Mr A. Oladele and Mr S. A. Salawu (Electricians) who all contributed immensely to bringing the work to this stage are all duly appreciated.

\section{REFERENCES}

Ademiluyi, T, Akpan, C (2007). Preliminary evaluation of fuel oil produced from pyrolysis of low density polyethylene water- sachet wastes. Journal of Applied Sciences and Environmental Management, 11(3): 15 - 19.

Aguado, J, Serrano, DP, Miguel, GS, Castro, MC, Madrid, S (2007). Feedstock recycling of Polyethylene in a two-step thermo-catalytic reaction system. Journal of Analytical and Applied Pyrolysis, 79: 415-423.
Aguado, J, Serrano, DP, Escola, JM (2006). Catalytic upgrading of plastic wastes, in feedstock recycling and pyrolysis of waste plastics, John Wiley \& Sons, Ltd: Spain. 73- 110.

Anuar Sharuddin SD, Abnisa, F, Wan Daud WMA, Aroua MK (2016). A review on pyrolysis of plastic wastes. Energy Conversion and Management, 115: 308-326.

Bendebane, F, Bouziane, L, Ismail, F (2010). Extraction of naphthalene: optimization and application to an industrial rejected fuel oil. Journal of Industrial and Engineering Chemistry, 16: 314 - 320 .

Gaurav, MM, Arunkumar, KN, Lingegowda, NS (2014). Conversion of LDPE plastic waste into liquid fuel by thermal degradation. International Journal of Mechanical and Production Engineering, 2(4) 104-110.

Hamilton, LJ, Cowart, JS, Luning-Prak, D, Caton, PA (2012) An experimental study of normal hexadecane and iso -dodecane binary fuel blends in a military diesel engine. Proceedings of the ASME 2010 Internal Combustion Engine Division Fall Technical Conference. 1-13.

Hopewell J, Dvorak R, Kosior E (2014) Plastics recycling: challenges and opportunities.

Philosophical Transactions of The Royal Society B, 364: 2115-2126.

Lin, Y (2009). Production of valuable hydrocarbons by catalytic degradation of a mixture of postconsumer plastic waste in a fluidized-bed reactor. Polymer Degradation and Stability, 94: $1924-1931$.

Martin- Gullon I, Esperanza M, Font R (2001) Kinetic model for the pyrolysis and combustion of poly - ethylene terephthalate (PET). Journal

*I ELETTA, OMODELE AA $;{ }^{2} A J A Y I, O A ;{ }^{3}$ OGUNLEYE, OO ${ }^{l}$ TIJANI, IA;

${ }^{I} A D E N I Y I, A G ;{ }^{1} A G B A N A, A S$ 
of Analytical and Applied Pyrolysis. 58-59: 635650.

Miandad, R, Barakat, MA, Aburiazaiza, AS, Rehan, M, Nizami, AS (2016). Catalytic pyrolysis of plastic waste: a review. Process Safety and Environmental Protection, 102: 822-838.

Miskolczi, N, Bartha, L, Borszeki J, Halmos P (2006). Determination of sulfur content of diesel fuels and diesel fuel-like fractions of waste polymer cracking. Talanta, 69(3): $776-780$.

Nizami, AS, Rehan, M, Ouda, OK, Shahzad, K, Sadef, Y, Iqbal, T, Ismail, IM (2015). An argument for developing waste-to-energy technologies in Saudi Arabia. Chemical Engineering Transactions, 45: 337-342.

Odebunmi, E.O., Ismaeel R.O., (2012). GC-MS characterization of Nigerian gulf heavy crude fractions. Elixir International Journal of Organic Chemistry, 42: 6472-6477.

Ohkita H, Nishiyama R, Tochihara Y, Mizushima T, Kakuta N, Morioka Y (1993) Acid properties of silica-alumina catalysts and catalytic degradation of polyethylene. Industrial \& Engineering Chemistry Research, 32(12): 3112-3116.

Palanivel, TM, Sulaiman, H (2014). Generation and composition of municipal solid waste (MSW) in Muscat, Sultanate of Oman, APCBEE Procedia, 10: $96-102$.

Ratnasari, DK, Nahil, MA, Williams, PT (2016). Catalytic Pyrolysis of waste plastics using staged catalysis for production of gasoline range hydrocarbon oils. Journal of Analytical and Applied Pyrolysis

. http://dx.doi.org/10.1016/j.jaap.2016.12.027
Sarker, M Rashid MM Rahman SR, Molla M (2012). Environmentally harmful low density waste plastic conversion into kerosene grade fuel. Journal of Environmental Protection, 3:700-708.

Senthilkumar T, Kumaragurubaran, B, Chandrasekar, M, Gnanasekaran, BM, Rajasekaran, J (2013). Combined effects of thermal barrier coating and blending with diesel fuel on usability of waste plastic oil in diesel engines. International Journal of Innovations in Engineering and Technology, 4: 240-246.

Sovova K, Ferus M, Matulkova I, Spanel P, Dryahina K , Dvorak O, Civis S, (2008) A study of thermal decomposition and combustion products of disposable polyethylene terephthalate (PET) plastic using high resolution fourier transform infrared spectroscopy, selected ion flow tube mass spectrometry and gas chromatography mass spectrometry. Molecular Physics, 106:1205 $-1214$.

Syamsiro, M, Cheng, S, Saptoadi, H, Norsujianto, T, Noviasri, P, Alimuddin, Z, Yoshikawa, K (2014) Fuel oil production from municipal plastic wastes in sequential pyrolysis and catalytic reforming reactors. Energy Procedia, 47: 180 188.

Uddin, MA, Koizumi, K, Murata, K, Sakata Y (1996) Thermal and catalytic degradation of structurally different types of polyethylene into fuel oil. Polymer. Degradation and Stability, 56:37-44.

United Nations Environment Programme (UNEP) (2009) Converting Waste Plastics to Resources compendium of Technology, 3-14 